\title{
O JUIZADO DE \\ GARANTIAS COMO \\ FATOR DETERMINANTE \\ À ESTRUTURAÇÃO \\ DEMOCRÁTICA DA \\ JURISDIÇÃO CRIMINAL: O \\ CONTRIBUTO DAS REFORMAS \\ PROCESSUAIS PENAIS \\ LATINO-AMERICANAS À \\ REFORMA PROCESSUAL \\ PENAL BRASILEIRA
}

THE COURT OF GUARANTEES AS A DETERMINING FACTOR FOR THE DEMOCRATIC STRUCTURING OF CRIMINAL JURISDICTION: THE CONTRIBUTION OF LATIN AMERICAN

CRIMINAL PROCEDURAL REFORMS TO BRAZILIAN CRIMINAL PROCEDURAL REFORM

EL JUZGADO DE GARANTÍAS COMO FACTOR DETERMINANTE A LA ESTRUCTURACIÓN

DEMOCRÁTICA DE LA JURISDICCIÓN CRIMINAL: EL CONTRIBUTO DE LAS REFORMAS PROCESALES PENALES LATINOAMERICANAS A LA REFORMA PROCESAL PENAL BRASILEÑA

\section{André Machado Maya ${ }^{1}$}

11 Doutor e mestre em Ciências Criminais pela PUCRS, especialista em Ciências Penais (PUCRS) e em Direito do Estado (UniRitter); professor de Direito Penal e Processual Penal do Programa de PósGraduação Strico Sensu (Mestrado) da Fundação do Ministério Público (FMP), em Porto Alegre, Rio Grande do Sul, Brasil; vice-presidente e sócio-fundador do Instituto Brasileiro de Direito Processual Penal (IBRASPP), com sede em Porto Alegre, Rio Grande do Sul, Brasil. Endereço eletrônico para contato: andremmaya@gmail.com. 
Resumo: O presente ensaio tem como objetivo examinar o instituto do juiz de garantias, como proposto no atual projeto de reforma do Código de Processo Penal brasileiro, e destacar a importância dessa nova figura à estruturação democrática da jurisdição criminal. A este efeito, proceder-se-á a uma abordagem comparada em relação ao juiz de garantias como previsto nas reformas processuais penais latino-americanas, identificando semelhanças e diferenças, para ao final destacar a necessidade de avançar em relação à proposta atual, identificando pontos determinantes à concepção do juiz de garantias como efetivo instrumento de democratização do sistema de justiça criminal. Palavras-chave: Jurisdição; juiz de garantias; reformas processuais penais; oralidade.

Abstract: The purposes of this essay are to examine the institution of the court of guarantees, as proposed in the current draft reform of the Brazilian Code of Criminal Procedure, and to emphasize the importance of this new figure for the democratic structuring of criminal jurisdiction. To this end, a comparative approach is taken with regard to the guarantee court as provided for in the Latin American criminal procedure reforms, identifying similarities and differences, in order to highlight the need to move forward with the current proposal, identifying determinant aspects of the design of the court of guarantees, as an effective instrument of democratization of the criminal justice system. Keywords: Jurisdiction; judge of guarantees; penal procedural reforms; orality.

Resumen: El presente ensayo tiene como objetivo examinar el instituto del juez de garantías, como el propuesto en el actual proyecto de reforma del Código de Proceso Penal brasileño, y destacar la importancia de esa nueva figura a la estructuración democrática de la jurisdicción criminal. En este efecto, se procede a un enfoque comparativo con relación al juez de garantías como previsto en las reformas procesales penales latinoamericanas, identificando semejanzas y diferencias, para finalmente destacar la necesidad de avanzar con relación a la propuesta actual, identificando puntos determinantes a la concepción de juez de garantías como efectivo instrumento de democratización del sistema de justicia criminal. Palabras-clave: Jurisdicción; juez de garantías; reformas procesales penales; oralidad.

\section{INTRODUÇÃO}

$s$ últimos trinta anos foram marcados por um intenso movimento de reformas legislativas nos países do bloco continental latino-americano, em parte justificado pela abertura democrática pós regimes ditatoriais, 
em outra parte motivada pela necessária atualização das respectivas legislações internas ao enunciado da Convenção Interamericana de Direitos Humanos, firmada em 1969, e às novas cartas constitucionais promulgadas nas últimas décadas do século XX. Especificamente no âmbito processual penal, praticamente todos os países latino-americanos reformaram ou estão em processo de reforma de suas respectivas legislações internas, adequando procedimentos até então marcadamente inquisitoriais a uma estrutura acusatória. No Brasil, atualmente, tramita no Congresso Nacional o Projeto de Lei 8045/2010, que visa à reforma do atual Código de Processo Penal, vigente desde 1941.

Um dos traços principais desse movimento reformista, para além da criação de instituições essenciais a um sistema processual penal minimamente democrático, é a separação das fases processuais, inerente à criação do juizado de garantias, órgão jurisdicional que substitui o antigo juiz de instrução e possui atuação específica na fase pré-processual, resguardando a imparcialidade dos magistrados competentes para o juicio oral. Sua implementação, porém, tem suscitado controvérsia entre os diferentes atores do campo jurídico brasileiro, cujas críticas são contundentes, embora nem sempre bem focadas.

O presente ensaio, então, alinhado à temática de Direito e Jurisdição da Revista Novos Estudos Jurídicos, busca examinar o instituto do juiz de garantias como proposto no PL 8045/2010 e destacar a sua importância ao efeito de adequar a atividade jurisdicional penal brasileira a um patamar democrático minimamente compatível com a principiologia enunciada na Convenção Interamericana de Direitos Humanos, da qual o Brasil é país signatário. Mais especificamente, o objetivo é demonstrar que os efeitos das reformas latino-americanas, neste ponto, vão além da mera substituição do juiz de instrução e da separação entre as fases processual e pré-processual, alcançando uma efetiva mudança cultural relacionada ao conceito de jurisdição, de acesso à justiça e de devido processo legal, na medida em que o modelo proposto com os juizados de garantia privilegia a oralidade como método de produção de decisões judiciais.

A este efeito, naturalmente, afigura-se fundamental o estudo comparado do proposto no PL 8045/2010 em relação às reformas processuais penais latinoamericanas, identificando semelhanças e diferenças. Pretende-se, ao final, pôr 
em evidência que a versão brasileira, em verdade, deixa a desejar em termos de avanço democrático, na medida em que não traz consigo a implementação de um sistema por audiências já na fase pré-processual. A este efeito, enfim, a primeira parte deste trabalho é destinada ao exame da atual formatação do juiz de garantias, como consta no Projeto de reforma do Código de Processo Penal que tramita na Câmara dos Deputados, enquanto a segunda parte tem por objeto o exame dessa figura como estruturada no processo penal reformado pelos países latino-americanos. Ao final, destacadas as diferenças, demonstrarse-á a necessidade de avançar em relação à proposta atual, identificando pontos determinantes à concepção do juiz das garantias como efetivo instrumento de democratização do sistema de justiça criminal.

\section{A regulamentação do juiz de garantias na reforma do Código de Processo Penal brasileiro}

Influenciado pelo movimento reformista que dominou os países latino-americanos na última década do século passado e nos primeiros anos deste terceiro milênio, de um lado, e pelo inequívoco fracasso das chamadas reformas parciais da legislação processual penal brasileira, de outro, o Senado Federal, por ato de seu então Presidente, nomeou uma Comissão de Juristas a quem foi dada a missão de elaborar um anteprojeto de reforma global do Código de Processo Penal. O trabalho apresentado por esta Comissão, ao final, resultou no Projeto de Lei do Senado $n^{\circ}$ 156/2009, cuja matriz acusatória, destacada na sua exposição de motivos, é posta em destaque com o afastamento do juiz em relação à atividade probatória no curso da fase investigativa, enunciada já no artigo $4^{\circ}$ do texto proposto.

Outro ponto diretamente relacionado à estruturação acusatória do projeto de reforma do Código de Processo Penal, também destacado na exposição de motivos do anteprojeto, é o intitulado juiz das garantias. O nome, a toda evidência, é influência do homônimo latino-americano, embora a origem dessa figura remonte ao ordenamento jurídico italiano, que na reforma da década de oitenta implementou o giudice per le indagini preliminari. Em essência, a designação de um magistrado com competência específica para atuação na fase pré-processual pretende atender a duas estratégias, a saber: o aprimoramento da atuação jurisdicional criminal própria desta fase e a minimização da contaminação 
subjetiva do juiz responsável pelo julgamento do processo, inerente ao contato (necessário) do magistrado com os elementos informativos colhidos na investigação criminal. ${ }^{2}$

Como proposto no PLS 156/2009, em apertada síntese, o juiz das garantias terá por atribuição, por exemplo, decidir sobre a adoção ou não de qualquer medida restritiva de direitos do investigado, bem como pela homologação ou não do flagrante delito. Será do juiz das garantias, também, a competência de resolver quaisquer questões que versem sobre o status libertatis do investigado e sobre requerimentos de produção antecipada de provas. Ademais, em uma interpretação combinada com o disposto no artigo $4^{\circ}$ do mesmo projeto, ao juiz das garantias é vedada a substituição probatória do órgão da acusação, sendo-lhe possível agir de ofício unicamente para fazer cessar eventual coação ilegal perpetrada contra o investigado. ${ }^{3}$ Nesse ponto, importante frisar, não há propriamente novidade em relação ao regramento processual penal atual, em que a função investigatória é atribuída à polícia, mediante controle externo do Ministério Público, restando ao magistrado o controle da legalidade da investigação e a tutela dos direitos e das garantias dos investigados. ${ }^{4}$

avanço inerente ao modelo proposto guarda relação, especificamente, com a diferenciação objetiva e bem determinada entre as fases preliminar e processual

2 "Para a consolidação de um modelo orientado pelo princípio acusatório, a instituição de um juiz de garantias, ou, na terminologia escolhida, de um juiz das garantias, era de rigor. Impende salientar que o anteprojeto não se limitou a estabelecer um juiz de inquéritos, mero gestor da tramitação de inquéritos policiais. Foi, no ponto, muito além. O juiz das garantias será o responsável pelo exercício das funções jurisdicionais alusivas à tutela imediata e direta das inviolabilidades pessoais. A proteção da intimidade, da privacidade e da honra, assentada no texto constitucional, exige cuidadoso exame acerca da necessidade de medida cautelar autorizativa do tangenciamento de tais direitos individuais. O deslocamento de um órgão da jurisdição com função exclusiva de execução dessa missão atende a duas estratégias bem definidas, a saber: a) a otimização da atuação jurisdicional criminal, inerente à especialização na matéria e ao gerenciamento do respectivo processo operacional; e b) manter o distanciamento do juiz do processo, responsável pela decisão de mérito, em relação aos elementos de convicção produzidos e dirigidos ao órgão da acusação." [PLS 156/2009. Exposição de motivos. Disponível em: http://legis. senado.gov.br/mate-pdf/58503.pdf]

3 Importante consignar que ao tempo da elaboração do anteprojeto de reforma não se perquiria sobre a realização de Audiência de Custódia no Brasil, motivo pelo qual não consta no artigo 14 do PLS a realização dessa audiência como uma das atribuições desse magistrado, o que, naturalmente, é por excelência competência sua.

4 A propósito: GIACOMOLLI, Nereu José; MAYA, André Machado. O juiz de garantias no projeto de reforma do Código de Processo Penal. In: PRADO, Geraldo; CHOUKR, Ana Claudia Ferigato; JAPIASSÚ, Carlos Eduardo Adriano. (Org.). Processo Penal e garantias: estudos em homenagem ao professor Fauzi Hassan Choukr. Florianópolis: Empório do Direito, 2015. p. 93-120. 
propriamente dita, do que decorre a atribuição da competência para o processo e o julgamento a um magistrado distinto daquele que atuou no curso da investigação. Neste ponto, a proposta opera uma efetiva ruptura em relação ao atual modelo de processo penal, superando, em definitivo, a regra da prevenção da competência, de difícil compatibilidade para com a garantia da imparcialidade. ${ }^{5}$ Com efeito, difícil crer na ausência de contaminação subjetiva de um juiz que, no curso das investigações, tomou contato com o material colhido nas interceptações telefônicas, com o resultado de uma quebra de sigilo, e proferiu decisões acerca do status libertais do investigado, impondo-Ihe a prisão cautelar, por exemplo. ${ }^{6}$

A figura do juiz das garantias, sob essa perspectiva, ao estabelecer a competência para julgamento a magistrado distinto do que atuou na investigação, contribui à maximização da garantia da imparcialidade, proporcionando que a fase processual destinada à produção probatória se desenvolva perante um juiz isento de "préjuízos", em condições de assegurar às partes tratamento igualitário e, ao réu, compatível com a presunção de inocência.

Tal contributo, no entanto, restou minimizado pelo próprio texto do Projeto de Lei em trâmite no Parlamento. Isso porque, segundo disposição do seu artigo 15, a competência do juiz das garantias cessa com a propositura da acusação, do que se deduz que o recebimento da denúncia é ato de competência do juiz do processo. Naturalmenteque tal ato pressupõe o exame dos elementos informativos produzidos na investigação, sem o que não é possível o juízo acerca da justa causa para o processo penal. Com isso, o pretendido distanciamento do juiz do processo em relação ao material investigativo resulta inequivocamente mitigado. Melhor seria, a fim de minimizar efetivamente as chances de contaminação subjetiva, que a competência para o recebimento da denúncia fosse atribuída ao juiz das garantias.

Não obstante isso, afigura-se possível identificar o juiz das garantias como um magistrado ao qual é dado zelar pela devida investigação criminal, o que inclui o dever de tutela dos direitos e das garantias fundamentais do investigado, de

5 MAYA, André Machado. Imparcialidade e Processo Penal: da prevenção da competência ao juiz de garantias. 2. ed. São Paulo: Atlas, 2014.

6 Em sentido oposto: ANDRADE, Mauro Fonseca. 0 juiz das garantias. 2. ed. Curitiba: Juruá, 2015. p. 84. 
um lado, e da eficiência da investigação, de outro. Por eficiência entende-se o efetivo esclarecimento dos fatos, em tempo razoável e com plena observância dos direitos e das garantias do investigado. Esta é a missão do juiz das garantias como desenhado no Projeto de Reforma do Código de Processo Penal brasileiro, cuja implementação efetiva alçará o modelo processual penal brasileiro a um patamar minimamente adequado ao standard democrático desenhado pelas normativas internacionais protetivas de direitos humanos.

\section{O juiz de garantias e o processo penal reformado dos países latino-americanos}

Impulsionados pelo movimento reformista europeu do final do Século anterior e diante da necessidade de adequação das legislações processuais penais internas ao paradigma humanitário enunciado pela Convenção Interamericana de Direitos Humanos, a quase totalidade dos países latino-americanos de colonização espanhola iniciou, no final dos anos noventa e na primeira década deste século, um movimento reformista orientado à estruturação acusatória do processo penal. $\mathrm{Na}$ abalizada doutrina de Julio Mayer, $^{7}$ essas reformas foram pensadas com o intuito de derrogar, de maneira definitiva, os diplomas legislativos de matriz inquisitorial introduzidos no continente como consequência da conquista e da colonização espanhola, ${ }^{8}$ cujas características, tais como a forma escrita e secreta, são próprias de estruturas judiciais extremamente burocráticas e verticais, sem independência e vinculadas a um poder político centralizado, do que decorre um modelo de processo em que o funcionário do Estado é o responsável por uma investigação solitária e inquisitorial. Um dos mais perceptíveis resultados desse movimento reformista foi a substituição do juiz de instrução pelo denominado juiz de garantias.

A pedra fundamental deste movimento reformista foi o Código de Processo Penal da Província de Córdoba, na Argentina, sancionado em 1939 e marcadamente influenciado pela legislação iluminista da Europa continental. ${ }^{9}$ Consoante

7 MAYER, Julio; STRUENSEE, Eberhard. Introducción. In: MAYER, Julio; AMBOS, Kai; WOISCHNIK, Jan. (Coord.). Las Reformas procesales penales en América Latina. Buenos Aires: Ad-Hoc, 2000. p. 17.

8 Que, segundo o autor argentino, predominaram no continente desde o Século XVIII, permanecendo inalteradas mesmo após a promulgação das Constituições de matriz liberal, no curso do Século XX.

9 Importante destacar que, antes disso, a Guatemala, em 1838, chegou a promulgar um Código de Processo Penal de viés acusatório, pautado no modelo de legislação processual penal elaborado por Edward Livingston, político e jurista do Estado norte-americano de Louisiana, que, todavia, não che- 
Mayer, a legislação cordobesa representou a superação da inquisição de matriz espanhola, fortemente influenciada pelos Códigos de processos italianos de 1913 e 1930, pela Ley de Enjuiciamento Criminal espanhola de 1882 e pela Ordenanza processual penal alemã. Além disso, constituiu a base com a qual, posteriormente, seria redigido o Código processual penal modelo ibero-americano, no qual se pautou a reforma processual da Costa Rica, no ano de 1973, assim como para as reformas legislativas que se seguiram à incipiente democratização dos países da região nas décadas de 1980 e 1990, dentre eles Guatemala (1992), Costa Rica (nova reforma, 1996), El Salvador (1996), Chile (2000), Venezuela (1998), Paraguai (1998) e Bolívia (1999). ${ }^{10}$

Observados os limites do presente ensaio, merece destaque aqui a fase investigatória. E quanto a este ponto, calha ressaltar a tendência verificada em países como Chile, Paraguai e Colômbia, assim como em algumas províncias argentinas, dentre elas a capital federal, Buenos Aires. Com o intuito de superar os problemas característicos do modelo inquisitivo e de se alinhar ao sistema acusatório, as novas legislações optaram por uma fase preliminar desformalizada, criativa, a cargo do Ministério Público e sob controle de um juiz de garantias. ${ }^{11}$

A este efeito, lecionam Falcone e Madina, a atribuição das funções investigatórias ao Ministério Público, com o consequente afastamento do juiz do controle da fase pré-processual, ademais de uma simples modificação legislativa e de nomenclatura, significou a efetiva inserção de um controle jurisdicional na fase investigatória, de modo que:

gou a entrar em vigor, pois revogado anos depois, com a queda do governo do progressista Gálvez (MAYER, Julio; STRUENSEE, Eberhard. Introducción. In: MAYER, Julio; AMBOS, Kai; WOISCHNIK, Jan. (Coord.). Las Reformas procesales penales en América Latina. p. 23/29).

10 MAYER, Julio; STRUENSEE, Eberhard. Introducción. In: MAYER, Julio; AMBOS, Kai; WOISCHNIK, Jan. (Coord.). Las Reformas procesales penales en América Latina. p. 23/29.

11 FALCONE, Roberto A.; MADINA, Marcelo A. El proceso penal en la provincia de Buenos Aires. Buenos Aires: Ad-Hoc, 2007, p. 87. A propósito, consta da Nota de Elevación do anteprojeto do Código de Processo Penal da Província de Buenos Aires (publicada pelo Senado da Província de Buenos Aires, La Plata, junho de 1996, p. 196 e sec., apud: BERTOLINO, Pedro J. El juez de garantías en el Código Procesal Penal de la Província de Buenos Aires. Buenos Aires: Depalma, 2000, p. 07): "procura de conferir el más alto grado de garantismo, se ha delineado la creación y actuación de un juez de garantías, presente a lo largo de toda la etapa de investigación penal preparatoria, como custodio de las reglas del debido proceso y del derecho a una adecuada defensa en juicio de las personas sometidas a persecución penal." 
[...] el juez de garantías debe controlar los posibles desbordes de dicha actividad perquisitiva, terciar en los conflictos que las partes puedan introducir, vigilar la estricta observancia de las garantías constitucionales, $y$, eventualmente, decidir sobre el mérito de las actuaciones para llevarla a juicio. ${ }^{12}$

Nesta mesma trilha, a reforma levada a cabo pelo Paraguai em 1998, ao pretender uma aproximação ao modelo acusatório de processo, teve na figura do juiz de garantias o principal destaque. Conforme Duarte, a investigação passou à responsabilidade do Ministério Público, que deve conduzi-la com auxílio da polícia, competindo ao juiz o controle acerca da forma de obtenção das evidências, a determinação de medidas cautelares pessoais ou patrimoniais, o juízo acerca da justa causa para o início do processo penal ou, ao contrário, de arquivamento provisório ou definitivo da investigação e, ainda, eventual aplicação de mecanismos alternativos de conclusão do procedimento, devendo fazer respeitar as garantias do investigado e assegurar a prova a ser produzida em juízo. ${ }^{13}$

No Chile, país referência em termos de reformas processuais penais no continente latino-americano, a superação do antigo modelo inquisitorial pelo novo formato acusatório trouxe consigo a recriação do Ministério Público, que havia sido extinto no país em $1927 .{ }^{14} \mathrm{O}$ novo Código de Processo Penal chileno definiu um sistema basicamente estruturado nos princípios de oralidade e de publicidade, estruturadores do que se entabulou denominar de juicio oral y público, realizado perante um tribunal composto por três magistrados que não tenham participado da fase preliminar. Tanto é consequência da criação do juiz de garantias e da

12 FALCONE, Roberto A.; MADINA, Marcelo A. El proceso penal en la provincia de Buenos Aires. $p$. 89. Destacam-se, ainda, como funções do juiz de garantias no Código de Processo Penal da Província de Buenos Aires: a) decidir sobre questões potencialmente restritivas de direitos fundamentais; b) decidir controvérsias entre o Ministério Público e as partes, ofendido ou investigado; c) intervir em tudo o que diga respeito à constituição das partes; d) decidir sobre a produção antecipada de provas; e) controlar a fase intermediária e decidir sobre a pronúncia ou não do investigado a juízo; f) vigiar e controlar a atividade da polícia e do Ministério Público, assegurando a objetividade da investigação e o respeito aos direitos fundamentais do suspeito; g) intervir nos casos de flagrância (FALCONE, Roberto A.; MADINA, Marcelo A. El proceso penal en la provincia de Buenos Aires. p. 67-78.).

13 DUARTE, Christian Bernal. Reforma del Proceso Penal en Paraguay y el Juez de Garantías y sus funciones. In: COUTINHO, Jacinto Nelson de Miranda; CARVALHO, Luis Gustavo Grandinetti Castanho de (Org.). O novo Processo Penal à luz da Constituição. Análise crítica do projeto de Lei n. 156/2009, do Senado Federal. Rio de Janeiro: Lumen Juris, 2010, p. 131 a 144.

14 RIEGO, Cristián. Chile. In: MAYER, Julio; AMBOS, Kai; WOISCHNIK, Jan (Coord.). Las Reformas procesales penales en América Latina. Buenos Aires: Ad-Hoc, 2000, p. 169. 
atribuição da investigação ao Ministério Público. Ao juiz de garantias compete tutelar os direitos dos envolvidos e a legalidade da investigação criminal, e também decidir sobre o encerramento das investigações e o início do processo, com o exame de admissibilidade das provas indicadas pelas partes, a definição do tribunal competente e do procedimento a ser seguido, e também dos limites da acusação. ${ }^{15}$

A reforma processual penal do Chile foi muito além da mera modificação legislativa, alcançando questões estruturais, econômicas e culturais. O investimento financeiro no sistema de justiça criminal foi elevado, alcançando 2\% do PIB nacional; as instituições essenciais ao funcionamento de um modelo acusatório de processo foram criadas, notadamente Ministério Público e Defensoria Pública, novos edifícios foram construídos e novos cargos de juízes foram criados. Além disso, houve investimento em capacitação, viabilizando que os antigos magistrados e servidores do Poder Judiciário compreendessem a essência da reforma e a ela aderissem. De outro lado, planos de aposentadoria foram incentivados, respeitando a opção daqueles que não pretendiam adaptar-se ao novo. Ademais, a implementação da reforma foi gradativa, iniciando-se pelas comarcas menores, no extremo do país, com implementação na capital quando já decorridos mais de cinco anos, o que viabilizou a resolução prévia de pontos de estrangulamento. Outro ponto que merece destaque é a denominada carga zero, a referir que as novas regras processuais se aplicam aos novos processos, seguindo os antigos procedimentos até então vigentes:

[...] a carga zero inicial permitiu que o novo sistema não iniciasse seu funcionamento assumindo a carga de trabalho do antigo sistema, já que esses delitos seguirão tramitando conforme as regras do anterior Código de Procedimento Penal. ${ }^{16}$

Por derradeiro, merece referência a reforma processual penal da Colômbia, datada de 1991, mesmo ano em que promulgada a Constituição Federal do país. O

15 RIEGO, Cristián. Chile. In: MAYER, Julio; AMBOS, Kai; WOISCHNIK, Jan (Coord.). Las Reformas procesales penales en América Latina. p. 179 e seg. São funções do juiz de garantias chileno: a) autorizar judicialmente os requerimentos do Ministério Público para medidas que privem, restrinjam ou perturbem os direitos assegurados na CF; b) conduzir as audiências da fase de investigação e decidir os incidentes que nela se verifiquem; c) decidir sobre a liberdade ou prisão preventiva dos suspeitos; d) dirigir a audiência preparatória do juízo oral; e e) decidir o procedimento abreviado.

Dados disponíveis em: http://rpp.minjusticia.gob.cl/. Acesso em: 02.07.2014. 
novo Código de Processo Penal estabelece um procedimento em que a primeira fase se constitui em uma investigação prévia facultativa e por uma instrução obrigatória, ambas conduzidas pelo Ministério Público, sob fiscalização do juez de control de garantias. Em qualquer delas, as medidas potencialmente restritivas de direitos fundamentais dependem sempre de autorização desse magistrado, cuja atuação restringe-se à fase preliminar. Para além da tutela dos direitos do investigado, é atribuição desse juiz a tutela da regularidade da investigação e, pois, dos direitos das vítimas e dos interesses da sociedade, do que é exemplo o juízo de proporcionalidade das medidas cautelares postuladas pelo Ministério Público no curso da instrução. ${ }^{17}$

Esse é o breve panorama do cenário de reformas processuais penais nos países latino-americanos. Resta, agora, a comparação entre esses modelos e o previsto no projeto de reforma do Código de Processo Penal brasileiro, ao que é dedicado o próximo tópico.

\section{O significado do juiz de garantias em um modelo de persecução penal por audiências}

É convergente a doutrina brasileira ao destacar como principal ponto positivo do instituto do juiz de garantias a separação que com ele se pretende estabelecer entre as fases pré-processual e processual propriamente ditas, do que resulta a almejada minimização dos fatores de contaminação subjetiva do julgador do processo. ${ }^{18}$

Efetivamente, o rompimento operado entre a investigação criminal e a instrução processual penal afigura-se determinante a este efeito e, consequentemente, ao intuito de maximizar a imparcialidade do magistrado. Isso na medida em que o julgador do processo permanecerá distante dos elementos informativos colhidos na investigação, não Ihe competindo decidir acerca de medidas investigativas potencialmente restritivas de direitos fundamentais, o que impõe

17 PERRALTA, Oscar Julián Guerrero. Colômbia. In: MAYER, Julio; AMBOS, Kai; WOISCHNIK, Jan. (Coord.). Las Reformas procesales penales en América Latina. Buenos Aires: Ad-Hoc, 2000, p. 197 e seg.

18 Neste sentido: LOPES JR., Aury; RITTER, Ruiz. A Imprescindibilidade do Juiz das Garantias para uma Jurisdição Penal Imparcial: Reflexões a partir da Teoria da Dissonância Cognitiva. Texto apresentado no II Encontro de Pós-Graduação Stricto Sensu em Ciências Criminais - IBRASPP. Canela/RS, Outubro/2016; GIACOMOLLI, Nereu José; MAYA, André Machado. O juiz de garantias no projeto de reforma do Código de Processo Penal. pp. 93-120; MAYA, André Machado. Imparcialidade e Processo Penal: da prevenção da competência ao juiz de garantias. 2. ed. São Paulo: Atlas, 2014. Em sentido oposto: ANDRADE, Mauro Fonseca. O juiz das garantias. p. 84. 
(necessariamente) a formação de um convencimento acerca do fato e sua autoria, ainda que prévio e horizontal.

Mas a isso não se resume a contribuição do juiz de garantias à democratização do processo penal. A razão de ser da criação desse órgão jurisdicional nos processos reformados dos países latino-americanos, de onde veio a inspiração para a proposta brasileira, possui uma justificativa bastante mais profunda, relacionada ao modelo de audiências inerente à adoção da oralidade como estrutura fundamental do que se denominou chamar de processo penal acusatório.

A propósito, em ensaio intitulado Elogio de la audiencia oral y pública, ${ }^{19}$ Binder destaca o papel da oralidade e do modelo de audiências nas reformas processuais penais latino-americana. Segundo o autor argentino, a importância do juicio oral y público para o modelo de administração de justiça dos Estados Democráticos está em reconhecer a oralidade como garantia secundária de três outras garantias que conformam o processo penal como instrumento de verificação da verdade construída pelas partes e destinada ao juiz: imparcialidade, contraditório e publicidade. ${ }^{20}$ Oralidade, prossegue Binder, ${ }^{21}$ pode ser definida como "o nome sintético que utilizamos para economizar explicações ao nos referirmos a um sistema judicial". Trata-se de um "conjunto de formas vinculadas a atos, sujeitos, tempo, espaço, coerção e caso", de uma "estrutura" que empresta sustentação à imparcialidade, ao contraditório e à publicidade. Dito de outra maneira, retrata uma metodologia de produção qualificada de informações e de comunicação entre os sujeitos do processo. ${ }^{22}$

19 BINDER, Alberto M. La implementación de la nueva justicia penal adversarial. Buenos Aires: Ad-Hoc, 2012, p. 217-235. Segundo o autor, a superação da inquisição pelos países da região vai muito além da mera discussão sobre mecanismos processuais, representando, em verdade, uma discussão sobre o modelo de sistema político e, como consequência, sobre o modelo de legalidade que se pretende ver aplicado ao processo penal. Ainda que admitido o compromisso com a verdade como base da legitimidade da atuação do juiz em uma República Democrática (legitimação política), disso não resulta que o magistrado seja um gestor de interesses no curso da persecução penal. Em vez de buscar a verdade, como se verificava nos modelos inquisitoriais, ao juiz nos Estados Democráticos é dado exigir a verdade das partes. Estas devem atuar como efetivas gestoras de interesses.

20 Também neste sentido: FERRAJOLI, Luigi. Derecho y razón: teoría del garantismo penal. 3.ed. Tradução de Perfecto Andrés Ibáñez e outros. Madri: Editorial Trotta, 1998. p. 563. Segundo o autor italiano, o procedimento oral constitui uma garantia secundária em relação às garantias epistemológicas, ditas primárias, de necessidade de uma acusação formulada por órgão distinto do julgador, de carga da prova e do contraditório.

21 BINDER, Alberto M. La implementación de la nueva justicia penal adversarial. p. 217-235.

22 DUCE, Mauricio; MARÍN, Felipe; RIEGO, Cristián. Reforma a los procesos civiles orales: consideraciones desde el debido proceso y calidad de la información, p. 35-41. Disponível em: http://biblioteca.cejamericas.org/bitstream/handle/2015/1220/reformaalos_procesoscivilesorales_ducemarinriego. 
Oralidade não é, pois, mera forma, não se confunde com a simples prevalência da fala sobre a escrita. Ao contrário, enuncia a opção por um modelo de justiça dinâmico, pautado na imediação, na continuidade, na concentração de atos e, como consequência, no contraditório substancial, compreendido este como participação efetiva das partes na construção da decisão judicial. ${ }^{23} \mathrm{~A}$ publicidade é o que diferencia a audiência do sistema inquisitivo da audiência do sistema acusatório, enquanto a imparcialidade é consequência desse modelo dinâmico em que a verdade é exigida das partes, e não produzida pelo julgador.

Neste cenário, a audiência oral assume a "centralidade política, técnica e cultural"24 de um novo modelo de justiça. Um modelo em que o magistrado não atua como gestor de interesses, pois sua legitimidade não está propriamente na busca da verdade, mas na verificação da verdade construída pelas partes. A audiência é o centro pelo qual essa verificação da verdade depende do contraditório e da imediação entre a prova produzida e o julgador, ${ }^{25}$ e também pelo qual a todos os acusados é assegurado o direito de chegar a essa fase processual, independentemente de que a maior parte dos casos seja resolvida pela via das soluções alternativas ao juicio oral. Ademais, é o centro pelo qual todas as decisões são proferidas em audiência, em substituição ao antigo modelo, em que o juiz decidia com base em papéis organizados na forma de um expediente, no mais das vezes sem qualquer contato com o imputado, como é comum ocorrer na fase pré-processual.

Neste ponto está o principal avanço das reformas, ao assegurar o tratamento do imputado como sujeito de direitos, permitindo-lhe o efetivo acesso ao Poder Judiciário, que se materializa pelo direito de audiência. A imediação para com o julgador proporciona ao imputado a possibilidade de expor sua versão, de ser ouvido efetivamente, de contradizer a acusação de maneira verdadeira, de fazer com que o juiz o perceba como sujeito de direitos, e não como uma folha de pdf?sequence=1\&isAllowed=y. Acesso em: 25.01.2017.

23 MAYA, André Machado. A oralidade como técnica de redução das práticas autoritárias no processo penal. Tese (Doutorado em Ciências Criminais). Faculdade de Direito. Pontifícia Universidade Católica do Rio Grande do Sul. Porto Alegre, 2015, p. 207.

24 BINDER, Alberto M. La implementación de la nueva justicia penal adversarial. p. 217-235.

25 A propósito, Diego Garcia Yomha e Santiago Martinez (La etapa preparatória en el sistema adversarial. Buenos Aires: Del Puerto, 2014, p. 74) destacam que a essência da audiência é "constituir o cenário para entregar informação de alta qualidade, com respeito aos princípios enunciados, com o fim de obter uma decisão jurisdicional." 
papel ou uma petição inserida em um expediente e associada a um número.

Aplicada essa lógica àfase pré-processual, osjuizados degarantias proporcionaram, no âmbito dos processos reformados, a concretização do direito de ser apresentado à (e ouvido pela) autoridade jurisdicional em um prazo razoável, como também das garantias de ampla defesa e do contraditório, observados os limites inerentes à fase investigativa. As denominadas audiencias de control de detención permitem a apresentação imediata do preso ao juiz de garantias, bem como o estabelecimento dos limites da investigação, possibilitando ao Ministério Público a imediata formalização da imputação (quando possível), o oferecimento de propostas de solução alternativa ao processo ou, então, o requerimento de prazo para conclusão da investigação. Neste último caso, decorrido este prazo, realiza-se nova audiência para formalização da imputação, exercício da defesa e da admissibilidade ou não da acusação formulada. Ainda, em se tratando de investigado preso, a qualquer tempo é possível a realização de audiência para verificação da legalidade ou necessidade da custódia. E sempre, em todos os casos, as medidas investigativas que se fizerem necessárias devem ser postuladas pelo Ministério Público - que conduz a investigação - ao juiz de garantias em audiência.

Aimplementação da oralidade nesta fase prévia aojuiciooralviabilizou a erradicação do expediente e, como consequência, a desformalização da investigação. Isso gera repercussão na forma de obtenção de informações durante a fase investigativa, no valor dado a essas informações e no modo de introdução desses informes durante os debates do juicio oral. Ao admitir a coleta de informações sem a necessidade de se observar regras rígidas e procedimentos burocráticos, o resultado é que este material acaba restrito à formação da opinio delicti do órgão acusatório, desprovido de qualquer valor probatório. Consequentemente, tornase necessária a reprodução dessa prova em juízo. Daí que o material coletado na investigação não possui um valor pré-determinado e absoluto, assim estabelecido em razão da autoridade de quem produziu a informação, e não do seu conteúdo propriamente dito. A investigação, a seu turno, torna-se dinâmica e mais eficaz, bem como sua cognição restrita ao efetivamente necessário à formalização da acusação. Como consequência, resguarda-se a centralidade do juicio oral, cuja prova será efetivamente produzida na presença dos julgadores. ${ }^{26}$

26 YOMBA, Diego Garcia; MARTINEZ, Santiago. La etapa preparatória en el sistema adversarial. $p$. 
Como visto, os juizados de garantia possuem um papel central na estruturação da persecução penal por audiências. Central porque a implementação de um modelo de processo pautado na oralidade, signo da democraticidade processual, pressupõe que todas as decisões sejam proferidas em audiência, inclusive as da fase pré-processual. Daí a importância da existência de magistrados com dedicação exclusiva à investigação criminal. Isentos da atribuição de instruir e julgar processos, estes podem atuar em regime de plantão permanente, dedicando a totalidade do seu tempo à realização das audiências características dessa fase prévia ao processo, seja de controle de detenção, seja para decidir sobre medidas cautelares ou sobre o status libertatis do investigado, seja para exame da admissibilidade da acusação. Como consequência, privilegiam-se o contraditório e o direito de defesa já na fase pré-processual, de um lado, e acelera-se a investigação, de outro. Uma vez que a cognição nesta fase é restrita ao necessário a sustentar a acusação, e que a prova deverá ser reproduzida no juicio oral, a tendência é a redução do tempo de duração da investigação. Disso decorre, naturalmente, a conclusão do processo penal em tempo razoável e a maior efetividade do sistema de justiça criminal, o que guarda direta relação com o tempo do processo. Ainda, afigura-se relevante observar que, na medida em que a investigação é deixada a cargo do Ministério Público, resulta facilitado ao juiz assumir a posição de efetivo garantidor da devida investigação criminal, do que resulta, em tese, um maior controle desta fase pré-processual e dos direitos e garantias fundamentais do investigado.

Inequivocamente, enfim, a ruptura para com a fase processual propriamente dita é um dado positivo a reforçar a importância dessa figura processual, mas o ponto principal a justificar a sua implementação é a viabilização do modelo de audiências que representa a coluna vertebral do modelo acusatório implementado com as reformas latino-americanas.

\section{CONSIDERAÇÕES FINAIS}

Do exposto é possível concluir, sem a pretensão de esgotamento das possibilidades de análise das questões que circundam a adoção do juiz de garantias nas reformas 
latino-americanas, que tal figura representa, no âmbito dos sistemas processuais penais reformados, algo bastante mais profundo do que a mera separação entre as fases investigativa e processual penal propriamente dita.

Como visto, o juizado das garantias afigura-se determinante à implementação da oralidade e do modelo de audiências já na fase pré-processual, contribuindo para a desformalização da investigação criminal, para o implemento (quanto possível) do contraditório e do direito de defesa, e qualificando seu resultado. Como consequência, acaba por reforçar a importância do juicio oral e, naturalmente, por potencializar o respeito aos direitos fundamentais do investigado na fase pré-processual. Não suficiente isso, a criação do juiz de garantias representa uma revolução própria das reformas latino-americanas, a simbolizar a ruptura para com as estruturas inquisitoriais até então vigentes, notadamente os juizados de instrução, figura inexistente na legislação processual penal brasileira.

Sob esta perspectiva, percebe-se que o avanço legislativo, no projeto de reforma do Código de Processo Penal brasileiro, não se estabelece na mesma perspectiva do que verificado nos demais países latino-americanos. A figura do juiz de garantias, como desenhada no PLS 156/09 - atual PL 8045/2010 -, não retrata modificação substancial em relação ao atualmente existente no Brasil, no tocante à atividade jurisdicional na fase investigativa. As atribuições deste magistrado, como disciplinadas no artigo 14 do projeto de reforma, são basicamente as mesmas hoje atribuídas aos magistrados no curso da fase pré-processual. A inovação se restringe, efetivamente, ao rompimento entre as fases da persecução penal, o que, no entanto, já ocorre em alguns Estados da Federação, onde há varas especializadas para a fase da investigação criminal, como no Estado de São Paulo.

Quanto ao mais, a manutenção do modelo burocrático de processo, pautado na escritura como forma por excelência dos atos processuais, na concentração de poderes na figura do juiz, no controle da investigação pela autoridade policial e na obrigatoriedade da ação penal, a título de exemplo, desnatura a real contribuição que esta figura poderia dar à democratização do processo penal brasileiro. Somado a isso, a ausência de regras efetivas de transição e de uma política de capacitação dos operadores jurídicos reforçam a dificuldade de se 
implementar uma efetiva modificação do modelo de processo. Daí a perspectiva de que, não obstante a importância do avanço, o juizado de garantias, na prática, não reproduza o efeito democratizante a ele atribuído. A comparação com as reformas dos demais países do continente evidencia que a incorporação dessa figura na reforma brasileira, desacompanhada da efetiva oralidade, não apresentará o efeito que dela se espera.

\section{REFERÊNCIAS DAS FONTES CITADAS}

ANDRADE, Mauro Fonseca. O juiz das garantias. 2.ed. Curitiba: Juruá, 2015.

BERTOLINO, Pedro. El juez de garantías en el Código Procesal Penal de la provincia de Buenos Aires. Buenos Aires: Depalma, 2000.

BINDER, Alberto $M$. La implementación de la nueva justicia penal adversarial. Buenos Aires: Ad-Hoc, 2012, p. 217-235.

CHIAVARIO, Mario. O Processo Penal na Itália. In: DELMÁS-MARTY, Mireille. (org.). Processo Penal e Direitos do Homem: rumo à consciência europeia. Barueri: Manole, 2004, p. 43-58.

CHOUKR, Fauzi Hassan. Garantias constitucionais na investigação criminal. Rio de Janeiro: Lumen Juris, 2006.

COUTINHO, Jacinto Nelson de Miranda. O papel do novo juiz no Processo Penal. In:

(Coord.). Crítica à Teoria Geral do Direito processual Penal. Rio de Janeiro: Renovar, $\overline{2001}$, p. 3-55

DELMÁS-MARTY, Mireille. À origem destes trabalhos. In: (Org.). Processo Penal e Direitos do Homem: rumo à consciência europeia. Barueri: Manole, 2004, p. xv-xviii.

DUARTE, Christian Bernal. Reforma del Proceso Penal en Paraguay y el Juez de Garantías y sus funciones. In: COUTINHO, Jacinto Nelson de Miranda; CARVALHO, Luis Gustavo Grandinetti Castanho de (Org.). O novo Processo Penal à luz da Constituição. Análise crítica do projeto de Lei n. 156/2009, do Senado Federal. Rio de Janeiro: Lumen Juris, 2010, p. 131-143.

DUCE, Mauricio; MARÍN, Felipe; RIEGO, Cristián. Reforma a los procesos civiles orales: consideraciones desde el debido proceso y calidad de la información. Justiça Civil: perspectivas para uma reforma en America Latina, Santiago do Chile. Disponível em: http:// biblioteca.cejamericas.org/ bitstream/handle/2015/1220/reformaalos_procesoscivilesorales_ ducemarinriego.pdf?sequence=1\&isAllowed=y. Acesso em: 25.01.2017

FALCONE, Roberto A.; MADINA, Marcelo A. El proceso penal en la provincia de Buenos Aires. Buenos Aires: Ad-Hoc, 2007.

FERRAJOLI, Luigi. Derecho y Razón - teoría del garantismo penal. 3.ed. Tradução de Perfecto Andrés Ibáñez e outros. Madri: Editorial Trotta, 1998.

GIACOMOLLI, Nereu José. Juiz de Garantias, um nascituro estigmatizado. In: MALAN, Diogo e MIRZA, Flávio (Org.). 70 Anos do Código de Processo Penal Brasileiro. Rio de Janeiro: Lumen Juris, 2012, p. 299-308.

GIACOMOLLI, Nereu José. Algumas marcas inquisitoriais do Código de Processo Penal brasileiro e as resistências às reformas. Revista Brasileira de Direito Processual Penal. São 
Paulo, nº 01, ano 01, Jul.-Dez./2014.

GIACOMOLLI, Nereu José. O Devido Processo Penal. Abordagem Conforme a Constituição Federal e o Pacto de São José da Costa Rica. São Paulo: Atlas, 2014.

GIACOMOLLI, Nereu José; MAYA, André Machado. O juiz de garantias no projeto de reforma do Código de Processo Penal. In: PRADO, Geraldo; CHOUKR, Ana Claudia Ferigato; JAPIASSÚ, Carlos Eduardo Adriano. [Org.]. Processo Penal e garantias: estudos em homenagem ao professor Fauzi Hassan Choukr. Florianópolis: Empório do Direito, 2015. p. 93-120.

GÓMEZ-COLOMER, Juan-Luís. Experiencias de Derecho comparado sobre la instrucción del proceso penal por el Ministerio Fiscal. In: GÓMEZ-COLOMER, Juan-Luís, GONZÁLEZ CUSSAC, José-Luis (Coord.). La Reforma de la Justicia Penal. Estudios en homenaje al Prof. Klaus Tiedemann. Jornadas sobre la Reforma de la Justicia Penal. Castelló de la Plana: Publicacions de la Università Jaume I: Servei de Publicacions, Disputació de Castelló, 1997, p. 459-496.

LOPES JR., Aury; RITTER, Ruiz. A Imprescindibilidade do Juiz das Garantias para uma Jurisdição Penal Imparcial: Reflexões a partir da Teoria da Dissonância Cognitiva. Texto apresentado no II Encontro de Pós-Graduação Stricto Sensu em Ciências Criminais - IBRASPP. Canela/RS, Outubro/2016.

MARTINEZ, Santiago; YOMHA, Diego Garcia. La etapa preparatória en el sistema adversarial. Buenos Aires: Del Puerto, 2014.

MAYA, André Machado. Imparcialidade e Processo Penal: da prevenção da competência ao juiz de garantias. 2.ed. São Paulo: Atlas, 2014.

MAYA, André Machado. O juiz das garantias no projeto de reforma do Código de Processo Penal. Boletim IBCCRIM, São Paulo, n 204, novembro/2009, p. 06-07.

MAYA, André Machado. A oralidade como técnica de redução das práticas autoritárias no processo penal. Tese (Doutorado em Ciências Criminais). Faculdade de Direito. Pontifícia Universidade Católica do Rio Grande do Sul. Porto Alegre, 2015.

MAYER, Julio; STRUENSEE, Eberhard. Introducción. In: MAYER, Julio; AMBOS, Kai; WOISCHNIK, Jan. (Coord.). Las Reformas procesales penales en América Latina. Buenos Aires: Ad-Hoc, 2000. p. 17-32

PERRALTA, Oscar Julián Guerrero. Colômbia. In: MAYER, Julio; AMBOS, Kai; WOISCHNIK, Jan. (Coord.). Las reformas procesales penales en América Latina. Buenos Aires: Ad-Hoc, 2000, p. 197-267.

RIEGO, Cristián. Chile. In: MAYER, Julio; AMBOS, Kai; WOISCHNIK, Jan. (Coord.). Las Reformas procesales penales en América Latina. Buenos Aires: Ad-Hoc, 2000. p. 167-196.

Recebido em: janeiro/2017

Aprovado em: junho/2017 